\title{
Measurement of the Plastic Viscosity and Yield Point of Drilling Fluids
}

\author{
D.N. Delikesheva ${ }^{1}$, A.Kh. Syzdykov ${ }^{1}$, J.A. Ismailova ${ }^{1, *}$, A.A. Kabdushev ${ }^{2}$, G.A. Bukayeva ${ }^{3}$ \\ ${ }^{I}$ Department of Petroleum Engineering, Satbayev University, Satpayev St., 22 - 050013, Almaty, Republic of Kazakhstan. \\ ${ }^{2}$ Department of Oil and Gas Business, Taraz State University named after M.Kh. Dulaty, Tole bi St., 60 -080000, Taraz, \\ Republic of Kazakhstan. \\ ${ }^{3}$ Department of Foreign Languages, Satbayev University, Satpayev St., 22 -050013, Almaty, Republic of Kazakhstan.
}

\begin{abstract}
:
Rheological parameters of drilling fluids, such as yield point and plastic viscosity, are required to determine the hydrodynamic components of pressure at various points in the circulation system during technological operations. It is essential to ensure a simple and accurate measurement of these parameters in the construction of oil and gas wells, however, existing methods are relatively expensive and the results obtained can be subjective. This article describes a newly developed method for measuring the plastic viscosity and yield point of the drilling fluid using a Marsh funnel, which will greatly simplify the procedure for determining the rheological parameters of drilling fluids and allow them to be measured directly on drilling rigs. When the geometrical parameters of the funnel are determined, the true viscosity parameters are calculated using simple formulas. The Marsh funnel is traditionally used on the drilling rig to measure the relative viscosity of the drilling fluid and is an inexpensive and simple device. The article provides comparative studies with standard methods for determining the rheological parameters of the drilling fluid. According to the results of the test method, comparisons are made of pressure losses in the circulation system of the drilling fluid on drilling rigs.
\end{abstract}

Keywords - Drilling Fluid, Marsh Funnel, Plastic Viscosity, Relative Viscosity, Rheological Parameters, Yield Point.

\section{INTRODUCTION}

Drilling fluids should be considered the most important variable for optimized drilling [1-2]. In this regard, they must have the appropriate properties required for a particular drilling operation. The characteristics of the drilling fluid flow, the selection of operating conditions for optimized drilling, well cleaning, wellbore stability, etc., depend on the appropriate drilling fluid rheology [3-4].

The key rheological characteristics affecting drilling fluids are plastic viscosity and yield point [5-8]. Without them, it is impossible to design the required flow rate of the flushing fluid, the upward velocity in the annular space, the diameter of nozzles in the flushing channel of the rock-cutting tool, the energy cost for circulation, as well as the energy cost required to overcome the friction between the drilling or casing string and the drilling fluid [6].
The rheological properties of drilling fluids are usually measured using multi-speed rotational viscometers with cylindrical working vessels or capillary viscometers [6-7]. In field conditions, rotational rheometers with coaxial cylinders are the most common [5-6].

The disadvantage of the above method consists in the complexity of the measuring device and procedure, high costs, as well as the unsuitability for field operations, which limits its use for monitoring drilling fluids directly on the drilling rig [7-8]. In addition, in order to increase the accuracy of defining viscosity by this method, it is advisable to repeat measurements to obtain the average values that will be closer to the true ones [9-10].

In real, well drilling conditions, the consistency of the drilling fluid is evaluated using a Marsh funnel. The Marsh funnel, invented by Hallan N. Marsh in 1931 [11], is traditionally used to quickly measure the relative viscosity of the drilling fluid in seconds, required to fill a given volume of fluid. It is an inexpensive tool, durable and easy to use. The disadvantage of this method is that the funnel viscosity alone cannot be directly used in hydraulic calculations, for example, in determining pressure losses in various parts of the circulation system of the drilling rig.

The present article describes a new method for measuring the rheological parameters of the drilling fluid, in particular, plastic viscosity (PV) and yield point (YP), based on defining its density and relative viscosity using a Marsh funnel, which will greatly simplify the procedure for determining the rheological parameters of drilling fluids and allow them to be measured directly on drilling rigs.

Pitt [2] carried out a number of studies to determine the effective viscosity of drilling fluids according to the Marsh funnel data using a rheological model of the power law.

Roussel and Roy [12] in their paper present an analysis of the rheological properties of cement-based grouts according to the Marsh funnel tests. The values of yield point and plastic viscosity were calculated with respect to the flow time of the cement grout, based on the Bingham rheological model.

In the work of Balhoff et al. [5], a Marsh funnel was used to measure rheological properties, in particular, the yield point of drilling fluids, and the results were compared with the

\footnotetext{
* Corresponding author (J.A. Ismailova).
}

Email: J.ismailova@satbayev.university 
readings of the Fann rotational viscometer. The authors calculated the wall yield rate using a non-linear viscosity ratio and concluded that the predicted yield rate deviates strongly at low yield stress, when the fluid level in the funnel is low enough.

Guria, Kumar and Mishra [8] present the results of a study, in which the yield point, apparent viscosity and plastic viscosity of the drilling fluid were determined using a Marsh funnel. Two variables for the analysis were the funnel drainage volume and the corresponding drainage time.

The work of Schoesser and Thewes [1], based on the same methodology [8], analyzes bentonite slurries using a digitized scale to measure the temporal fluid height in a Marsh funnel. They gave the dependence of yield stress on the strain rate, although their results were significantly different from other standard viscometer measurements.

All attempts to use the March funnel to determine the two parameters of the true viscosity of the drilling fluid, namely yield point and plastic viscosity, were characterized by the addition of new complex structural elements and complex mathematical calculations, which did not contribute to cost reduction.

\section{MATERIAL AND METHODS}

Experimental studies were conducted to compare the results of the developed method for determining the yield point and plastic viscosity of the drilling fluid with the data provided by the widely used 6-speed Fann 35 rotational viscometer. Tests were carried out on a drilling fluid based on slowly dissolving clay powder (bentonite). Relative viscosity measurements were carried out using a VBR-2 funnel (an analog of the Marsh funnel), and density measurements - using a pycnometer (mud balance). Comparisons were made of pressure losses along the circulation path of the drilling fluid on drilling rigs of the $\mathrm{X}$ and $\mathrm{Y}$ fields. The Turbo Basic language program was used to calculate the yield point and plastic viscosity of the drilling fluid.

\section{THEORETICAL STUDIES}

The proposed method is carried out by measuring the flow time of a given fluid volume from a measuring funnel, followed by measuring the fluid volume flowing in half of this time. If the total flow time for relative viscosity measurements always corresponds to the same measured volume $\mathrm{V}_{\mathrm{M}}$, then half of this time must also correspond to the same determined volume. The latter is thus a characteristic of relative viscosity measurements using a funnel of this type and is found once, i.e., it does not need to be defined repeatedly during each relative viscosity measurement in order to determine yield point and plastic viscosity.

Based on the known values of the flow time of a given measured fluid volume $V_{M}$ (i.e., its relative viscosity) and its volume $\mathrm{V}_{\mathrm{MT}}$ flowing in half of this time, the following sequence of calculations is performed.
The average velocity of the fluid moving along the nozzle during the flow of the measured volume is as follows:

$$
\vartheta=\frac{4 V_{M}}{\pi d^{2} T}
$$

where $\mathrm{d}$ is the diameter of the flow section of the nozzle channel, $\mathrm{T}$ is the relative viscosity obtained in the experiment.

The time-average outflow height of the measured volume is as follows:

$$
H_{M T}=H_{K}+L-d /(2 \operatorname{tg} \beta)
$$

where $\beta$ is the coning angle of the funnel 1 ; $L$ is the length of the nozzle $2: \mathrm{H}_{\mathrm{K}}$ is the component of the height $\mathrm{H}_{\mathrm{MT}}$, falling on the cone of the funnel:

$$
H_{K}=\sqrt[3]{\frac{3\left(V-V_{M T}\right)}{\pi(\operatorname{tg} \beta)^{2}}}
$$

where $\mathrm{V}$ is the total fluid volume in the funnel, $\mathrm{V}_{\mathrm{MT}}$ is the fluid volume flowing in half of the total measurement time, i.e., 0.5T. As indicated above, this volume is determined experimentally.

The average time of measurement of the hydrostatic fluid pressure in the funnel [13] is as follows:

$$
\rho g H_{M T}=\lambda \rho L \frac{\vartheta^{2}}{2 d}+\rho \frac{\vartheta^{2}}{2 a^{2}},
$$

where $\rho$ is the fluid density, $g$ is the gravitational acceleration; $\lambda$ is the time-average flow coefficient of hydraulic resistance when the fluid moves along the nozzle; $a$ is the compression ratio of the flow.

The equation shows that when the fluid flows out of the measuring funnel, the hydrostatic pressure (the left side of the equation) is spent on the pressure loss due to the friction when the fluid moves along the nozzle and on its compression when it moves down the funnel. The possible values of the compression coefficient of the flow "a" are indicated above.

Equation (4) is solved relative to the hydraulic resistance coefficient:

$$
\lambda=\frac{\left(g H_{M T}-\left(\vartheta^{2} /\left(2 a^{2}\right)\right) 2 d\right.}{L \vartheta^{2}}
$$

The Reynolds criterion for non-Newtonian (possessing the yield point) fluids is

$$
\operatorname{Re}=\frac{\rho \vartheta d}{\left(\eta+\tau \frac{d}{6 \vartheta}\right)}
$$

where $\eta$ and $\tau$ are plastic viscosity and yield point, respectively.

On the other hand, the Reynolds criterion can be calculated from the hydraulic resistance coefficient $\lambda$ found above. In particular, in the laminar motion regime, which always takes 
place when non-Newtonian fluids (drilling fluids) [13-14] flow out of the measuring funnel, it is equal to:

$$
\operatorname{Re}=64 / \lambda
$$

Based on formulas (6) and (7), the desired equation for the interdependence of the two viscosity parameters can be obtained:

$$
\eta+\tau \frac{d}{6 \vartheta}=\frac{\lambda \rho \vartheta d}{64}
$$

An analysis of the equation shows that, under the conditions of this particular measurement, the coefficients at $\eta$ and $\tau$ are constant.

Among the quantities used in the calculation, $\mathrm{d}$ and the coefficient "a", the constant geometrical parameters of the funnel, Vм, Нмт, the constant values characterizing relative viscosity measured by the funnel, $\rho$ and $T$, the measured values of the parameters used in true viscosity calculations, and finally $\vartheta$ and $\lambda$ are obtained using the above constant values. Therefore, for the conditions of this particular measurement, they are also constant. Based on the foregoing, formula (8) can be written as:

$$
\eta+A \tau=B
$$

This means that there is an inverse linearity between the desired parameters of plastic viscosity and yield point.

With the constant coefficients $\mathrm{A}$ and $\mathrm{B}$, the viscosity of a given drilling fluid, considered as a whole, is characterized by a family of combinations $\eta$ and $\tau$. If one of these parameters is increased from 0 to maximum, the second will linearly decrease from maximum to zero. If we continue to increase the "argument", the "function" will take negative values, which is physically impossible. Thus, zero values determine the boundaries of the possible combinations of $\eta$ and $\tau$. Based on linearity and known boundaries, a simple way to find the most probable average combinations of $\eta$ and $\tau$ is obtained.

At $\tau=0$, we have the maximum possible value of plastic viscosity:

$$
\eta_{M A X}=\frac{\lambda \rho \vartheta d}{64}
$$

However, due to the linear nature of the dependence, it can be concluded that the most probable average value is equal to half the maximum, i.e.:

$$
\eta_{M T D}=\frac{\lambda \rho \vartheta d}{128}
$$

Based on formula (8), the corresponding most probable average value of yield point is obtained:

$$
\tau_{M E D}=\left(\frac{\lambda \rho \vartheta d}{64}-\eta_{M E D}\right) \frac{6 \vartheta}{d}
$$

or

$$
T_{M E D}=\frac{6 \lambda \rho \vartheta^{2}}{128}
$$

\section{RESULTS AND DISCUSSION}

The relative viscosity calculated using the FUNNEL4 program was accepted as a criterion for the comparability of

\begin{tabular}{|c|c|c|c|c|c|c|c|c|}
\hline \multirow[t]{2}{*}{ No } & \multirow[t]{2}{*}{ Density, $\mathrm{kg} / \mathrm{m}^{3}$} & \multicolumn{2}{|c|}{ FANN35 } & \multirow{2}{*}{$\begin{array}{c}\text { FUNNEL4, } \\
\mathrm{s}\end{array}$} & \multirow{2}{*}{$\begin{array}{c}\text { VBR-2 } \\
\text { T, s }\end{array}$} & \multicolumn{2}{|c|}{ Proposed method } & \multirow{2}{*}{$\begin{array}{c}\text { FUNNEL4, } \\
\mathrm{s}\end{array}$} \\
\hline & & $\begin{array}{c}\dot{\eta}, \\
\mathrm{Pa}^{*} \mathrm{~s}\end{array}$ & $\begin{array}{l}\tau, \\
\mathrm{Pa}\end{array}$ & & & $\begin{array}{l}\text { nं, } \\
\mathrm{Pa}^{*} \mathrm{~s}\end{array}$ & $\begin{array}{c}\tau, \\
\mathrm{Pa}\end{array}$ & \\
\hline & 1 & 2 & 3 & 4 & 5 & 6 & 7 & 8 \\
\hline 1 & 1025 & 0.001 & 0 & 1624 & 15.22 & 0.0017 & 4.02 & 15.89 \\
\hline 2 & 1050 & 0.001 & 0.48 & 15.55 & 15.37 & 0.0019 & 4.30 & 15.93 \\
\hline 3 & 1075 & 0.0015 & 0.48 & 15.65 & 15.47 & 0.0020 & 4.52 & 15.95 \\
\hline 4 & 1100 & 0.002 & 0.48 & 15.72 & 15.49 & 0.002 & 4.65 & 15.91 \\
\hline 5 & 1125 & 0.002 & 0.72 & 15.73 & 15.63 & 0.0022 & 4.93 & 16.13 \\
\hline 6 & 1150 & 0.003 & 0.72 & 15.84 & 15.70 & 0.0023 & 5.12 & 16.03 \\
\hline 7 & 1175 & 0.003 & 0.96 & 15.84 & 16.03 & 0.0026 & 5.63 & 16.74 \\
\hline 8 & 1200 & 0.004 & 0.96 & 15.92 & 16.31 & 0.0028 & 6.08 & 16.72 \\
\hline 9 & 1225 & 0.0045 & 1.44 & 16.22 & 17.22 & 0.0035 & 7,18 & 17.72 \\
\hline 10 & 1250 & 0.005 & 3.12 & 17.10 & 18.10 & 0.0042 & 8.15 & 18.61 \\
\hline 11 & 1275 & 0.006 & 5.04 & 18.52 & 19.85 & 0.0054 & 9.67 & 20.35 \\
\hline 12 & 1300 & 0.0085 & 7.44 & 21.72 & 22.31 & 0.0071 & 11.27 & 22.88 \\
\hline 13 & 1300 & 0.009 & 6.96 & 21.92 & 22.69 & 0.0073 & 11.45 & 23.26 \\
\hline 14 & 1325 & 0.0115 & 15.36 & 31.89 & 39.87 & 0.0171 & 15.25 & 40.55 \\
\hline 15 & 1350 & 0.0125 & 27.60 & 76.08 & 85.15 & 0.0496 & 16.89 & 86.90 \\
\hline
\end{tabular}
the results. After entering the values of plastic viscosity and yield point into the program, the relative viscosity measured by a funnel with specified geometric parameters was obtained (Table 1).

Table 1. Comparison of the viscosity values determined by the FANN35 device and the proposed method using the ETTA1 computer model (compiled by formulas (1) - (13) 
International Journal of Engineering Research and Technology. ISSN 0974-3154, Volume 13, Number 1 (2020), pp. 58-65 (C) International Research Publication House. http://www.irphouse.com

Each row of Table 1 was composed as follows:

- The viscosity values measured by the FANN35 device (columns 2 and 3 ) to obtain the corresponding funnel viscosity (column 4) were entered into the FUNNEL4 program calibrated on water, a computer model of the standard VBR-2 funnel.

- The actual funnel viscosity measured by VBR-2 (column 5) was entered into the ETTA1 program, which, according to the above algorithm, provided the values of plastic viscosity and yield point (columns 6 and 7).

- Then the obtained values were also entered into the FUNNEL program, while obtaining the funnel viscosity (column 8).

The table data are presented in the following graphs (Fig. 1$3)$.

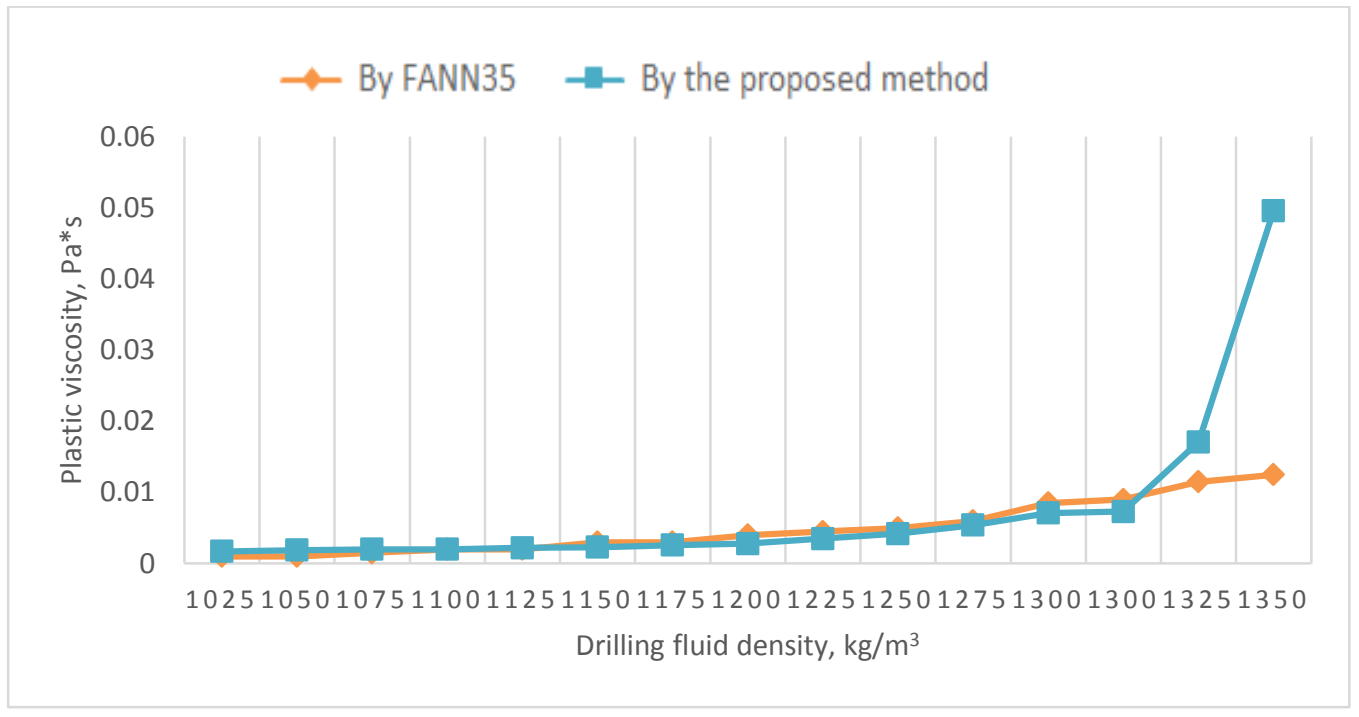

Fig. 1. Dependence of the fluid plastic viscosity on the density according to FANN35 and the proposed method

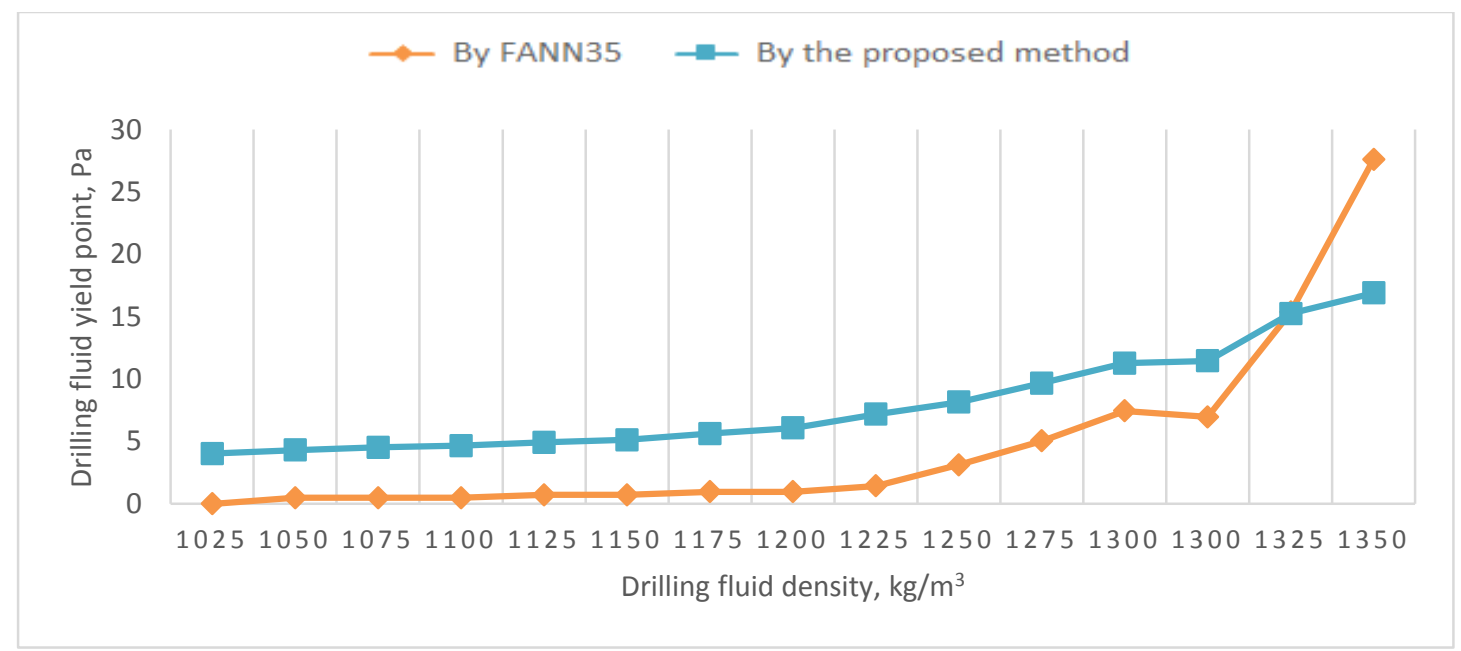

Fig. 2. Dependence of the fluid yield point on the density according to FANN35 and the proposed method 
International Journal of Engineering Research and Technology. ISSN 0974-3154, Volume 13, Number 1 (2020), pp. 58-65

(C) International Research Publication House. http://www.irphouse.com

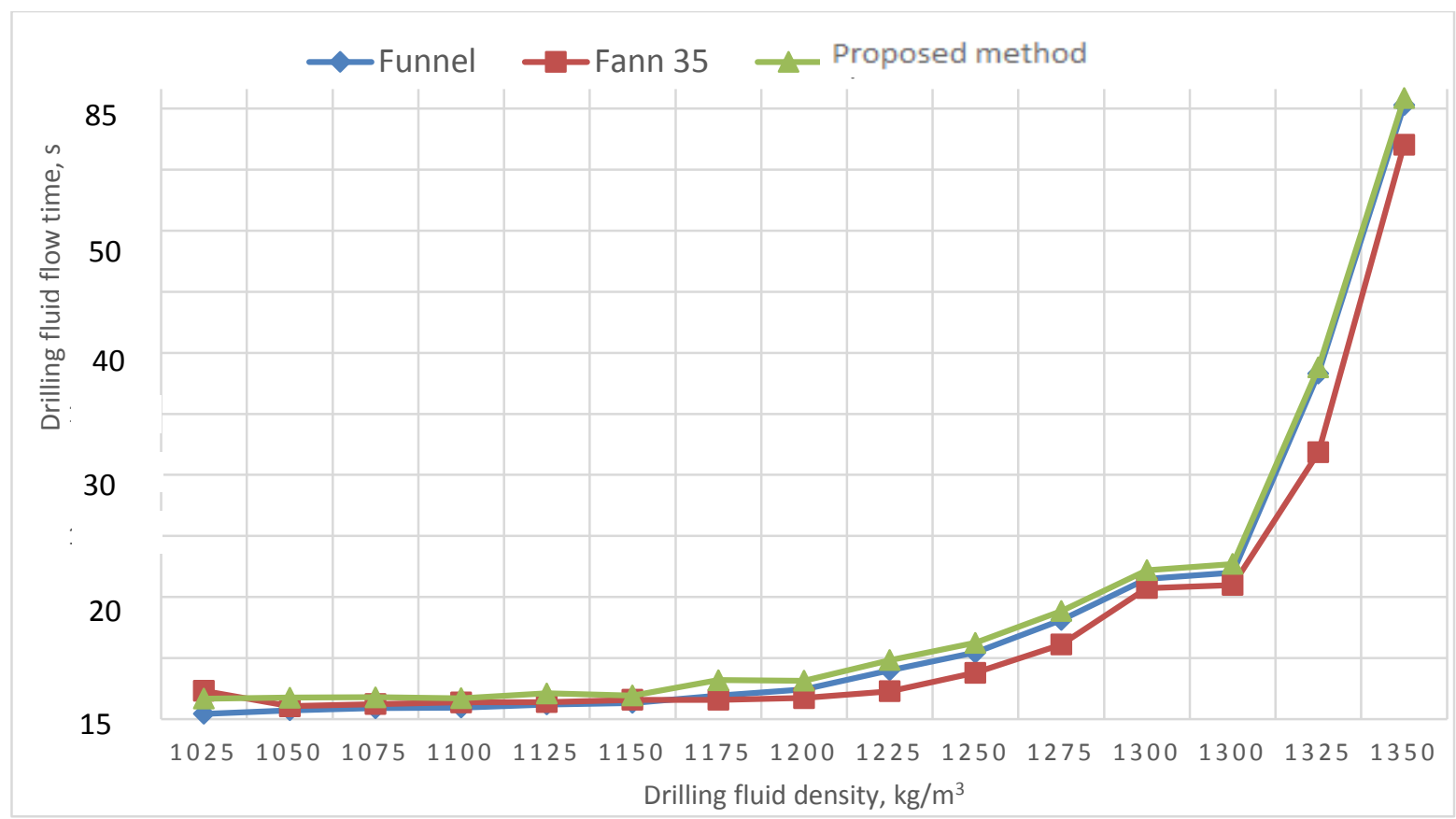

Fig. 3. Dependence of the viscosity values obtained directly by VBR-2 and those recalculated by FUNNEL4, as well as the values of plastic viscosity and yield point determined by FANN35 and the proposed method on the fluid density

Fig. 1 shows that up to a density of $1,300 \mathrm{~kg} / \mathrm{m}^{3}$ there is a strong convergence between the values of plastic viscosity obtained by both methods. However, with a further increase in density, the ETTA1 chart (orange) goes up, sharply increasing and diverging from the FANN35 chart.

Fig. 2 shows that the values of yield point according to ETTA1 up to a density of $1,300 \mathrm{~kg} / \mathrm{m}^{3}$ are $4-5 \mathrm{~Pa}$ higher that those related to FANN35. Further, however, the latter sharply increase and outrun the former.

In this respect, the pattern is opposite to that shown in Fig. 1, where the plastic viscosity related to ETTA1 sharply increases for the same density values. These opposite mismatches, as a whole, substantially cancel each other out, as evidenced by the graph of the combined indicator shown in Figure 3. The combined indicator includes the values of relative viscosity, which are close to each other in all three graphs.

Based on the data in Table 1, an analysis was made of the deviations of the values of relative viscosity obtained by FANN35 and ETTA1 recalculations from the actual results of VBR-2 funnel measurements. The results of the analysis are shown in Table 2.

Table 2. Analysis of deviations of the virtual values of relative viscosity from the actual values obtained by VBR-2 funnel measurements, \%

\begin{tabular}{|c|c|c|c|c|c|c|c|c|c|c|}
\hline $\begin{array}{l}\text { Line number from } \\
\text { Table } 1\end{array}$ & 1 & 2 & 3 & 4 & 5 & 6 & 7 & 8 & 9 & 10 \\
\hline FANN35 & 6.7 & 1.2 & 1.2 & 1.5 & 0.6 & 0.6 & -1.2 & -2.4 & -5.8 & -5.5 \\
\hline ETTA1 & 4.4 & 3.7 & 3.1 & 2.6 & 3.2 & 2.6 & 2.7 & 2.5 & 6.2 & 2.8 \\
\hline With a correction & 1.4 & 0.7 & 0.1 & -0.4 & 0.2 & -0.4 & -0.3 & -0.5 & 3.2 & -0.2 \\
\hline $\begin{array}{l}\text { Line number } \\
\text { Table } 1\end{array}$ & 11 & 12 & 13 & 14 & 15 & $\begin{array}{c}\text { Mean } \\
\text { deviation }\end{array}$ & \multicolumn{2}{|c|}{$\begin{array}{c}\text { Sum of squared } \\
\text { deviations }\end{array}$} & \multicolumn{2}{|c|}{$\begin{array}{l}\text { Standard } \\
\text { deviation }\end{array}$} \\
\hline FANN35 & -6.7 & -2.6 & -3.4 & -20.0 & -10.7 & 3.03 & \multicolumn{2}{|c|}{284.54} & \multicolumn{2}{|c|}{3.73} \\
\hline ETTA1 & 2.5 & 2.6 & 2.5 & 1.7 & 2.1 & 3.01 & \multicolumn{2}{|c|}{152.80} & \multicolumn{2}{|c|}{1.13} \\
\hline With a correction & -0.5 & -0.4 & -0.5 & -1.3 & -0.9 & 0.73 & \multicolumn{2}{|c|}{16.56} & \multicolumn{2}{|c|}{0.63} \\
\hline
\end{tabular}

When compiling the table, the following was taken into account:

- Absolute values were used to derive the mean deviations.

- In the context of FANN35, the deviations for experiments No. 14 and No. 15 were clearly out of the series (they represent the so-called "misses" in statistics); therefore, the analysis did not include them (like in case of ETTA1) and covered 13 experiments in total.

The analysis of the deviations makes it possible to draw the following conclusions: 
- By FANN35, the deviation signs are positive up to No. 7, then, decreasing, they change to negative. On lines No. 5 and No. 6, these values are very close to VBR2, which confirms the adequacy of the FUNNEL4 program. For No. 7, the module values fluctuate, and for No. 14, they deviate from VBR2 so sharply that they raise doubts about the correct operation of the device.

- By the developed method (ETTA1 program), the mean deviations are almost the same as by FANN35. However, these data are characterized by a much smaller scatter - their mean

square deviation is 3.3 times less than by FANN35. The deviations are only positive and, therefore, they are largely systematic (flaws in the ETTA1 program). By accepting the mean error as a correction term and subtracting it from the obtained values of relative viscosity, one can sharply increase the accuracy (bring the calculated data closer to the results of VBR-2 measurements). Then, as it follows from Table 2, the mean deviation decreases by 4.1 times, and the mean square deviation - by 1.8 times.

\section{IV.I Production tests}

Based on the considered method, comparisons were made of pressure losses along the circulation path of the flushing fluid on drilling rigs of the $\mathrm{X}$ field. The density and relative viscosity of the drilling fluid were measured, which determined the most probable values of plastic viscosity and yield point. After that, using a hydraulic program, pressure losses were determined and compared with the pressure gauge readings on the drilling pump. The measurement conditions and the pressure defined by the gauge are shown in Table 3.

Table 3. Circulation conditions of the drilling fluid in the well

\begin{tabular}{|c|c|c|c|c|c|c|c|c|c|c|}
\hline $\begin{array}{c}\mathrm{L}_{\mathrm{w}} \\
\mathrm{m}\end{array}$ & $\begin{array}{l}\mathrm{D}_{\mathrm{W}}, \\
\mathrm{mm}\end{array}$ & $\begin{array}{l}\mathrm{D}_{\mathrm{DP}} \\
\mathrm{mm}\end{array}$ & $\begin{array}{l}\mathrm{D}_{\mathrm{PJ}}, \\
\mathrm{mm}\end{array}$ & $\begin{array}{c}\mathrm{L}_{\mathrm{DC}} \\
\mathrm{m}\end{array}$ & $\begin{array}{c}\mathrm{D}_{\mathrm{DC}} \\
\mathrm{mm}\end{array}$ & $\begin{array}{c}\mathrm{Q} \\
1 / \mathrm{min}\end{array}$ & $\begin{array}{c}\mathrm{P} \\
\mathrm{kg} / \mathrm{m}^{3}\end{array}$ & $\begin{array}{l}\mathrm{T} \\
\mathrm{s}\end{array}$ & $\begin{array}{c}\mathrm{V}, \\
\mathrm{m} / \mathrm{h}\end{array}$ & $\begin{array}{c}\mathrm{P}_{\mathrm{G}} \\
\mathrm{mPa}\end{array}$ \\
\hline 600 & 161 & $89 / 71$ & $108 / 49$ & 24 & $120 / 47$ & 540 & 1150 & 27 & 6.6 & 1.7 \\
\hline 416 & 161 & $50 / 39$ & $65 / 28$ & 15 & $73 / 35$ & 210 & 1220 & 39 & 0 & 2.5 \\
\hline
\end{tabular}

The studies were conducted in two vertical open-hole wells (in wells of the $\mathrm{X}$ field, casing pipes are sunk only when drilling is completed). A $600 \mathrm{~m}$ deep well was drilled by KZ800A, a Japanese-made rig, equipped with a scoreboard, demonstrating the parameters of the drilling regime and including the fluid flow, the drilling pump pressure and the penetration rate. During manual measurements of density and relative viscosity, the latter was defined at the rate of $6.6 \mathrm{~m} / \mathrm{h}$. A $416 \mathrm{~m}$ deep well was drilled by the ZIF 1200 installation. At the time of measurements, it was in the flushing process.
Based on density and relative viscosity measurements, the plastic viscosity and yield point of the drilling fluid were calculated by the above method. Using them, together with the parameters indicated in the table, pressure losses were calculated when the fluid moved down the drill pipe and the drill collar and up the annular space. The hydraulic program also determined pressure losses due to the excess density of the sludge upstream relative to the cleaned downstream. The calculation results are shown in Table 4.

Table 4. Calculation of pressure losses in wells

\begin{tabular}{|c|c|c|c|c|c|c|c|c|c|c|}
\hline \multicolumn{2}{|c|}{ Viscosity } & \multicolumn{7}{|c|}{ Pressure losses, $\mathrm{mPa}$} & \multicolumn{2}{|c|}{ Total } \\
\hline $\begin{array}{c}\eta \\
\mathrm{Pa}^{*} \mathrm{~s}\end{array}$ & $\begin{array}{c}\tau, \\
\mathrm{Pa}\end{array}$ & DP & DPJ & DP-W & DPJ-W & $\mathrm{DC}$ & DC-W & $\mathrm{S}$ & $\mathrm{mPa}$ & $\%$ \\
\hline 0.0089 & 11.47 & 0.653 & 0.434 & 0.264 & 0.010 & 0.197 & 0.021 & 0.032 & 1.61 & 95 \\
\hline 0.0154 & 13.97 & 1.448 & 0.728 & 0.145 & 0.009 & 0.126 & 0.007 & 0 & 2.46 & 98 \\
\hline \multicolumn{11}{|c|}{ Note: The top line is a $600 \mathrm{~m}$ deep well, the bottom is a $416 \mathrm{~m}$ deep well. } \\
\hline \multicolumn{11}{|c|}{$\begin{array}{l}\text { DP is the pressure loss inside the drill pipes; DPJ is the pressure loss in their joints; DP-W is the pressure loss in } \\
\text { the space between the drill pipe and the well; DC is the pressure loss inside the drill collar; DC-W is the pressure } \\
\text { loss in the space between the drill collar and the well; } \mathrm{S} \text { is the pressure loss of removing sludge. }\end{array}$} \\
\hline
\end{tabular}

Table 4 shows that the difference between the calculated and actual (by the pump pressure gauge) values was $5-2 \%$.
Similar work was carried out at the Y oil field, but the parameters of the true viscosity of the drilling fluid were also 
determined using a FANN35 rotational viscometer, which made it possible to compare both methods.

The study used the drilling rig ZJ-20. It has a conductor $450 \mathrm{~m}$ long with an outer diameter of $245 \mathrm{~mm}$ and an inner diameter of $226.7 \mathrm{~mm}$. The diameter of an open hole is $220.7 \mathrm{~mm}$. The drilling bit of PDC type was used, with six (three $14 \mathrm{~mm}$ and three $16 \mathrm{~mm}$ ) hydraulic nozzles. The drill pipes have a diameter of 102/85 $\mathrm{mm}$ and an internal collar diameter of 65 $\mathrm{mm}$. The drill collars are $82 \mathrm{~m}$ long with an inner diameter of $65 \mathrm{~mm}$ (Table 5-6).

Table 5. Measurement conditions in the well of the Y field

\begin{tabular}{|c|c|c|c|c|c|c|c|c|c|c|}
\hline \multirow{2}{*}{$\begin{array}{c}\mathrm{L}_{\mathrm{w}} \\
\mathrm{m}\end{array}$} & \multirow{2}{*}{$\begin{array}{c}\mathrm{LOH}_{\mathrm{OH}} \\
\mathrm{m}\end{array}$} & \multirow{2}{*}{$\begin{array}{c}\mathrm{V} \\
\mathrm{m} / \mathrm{h}\end{array}$} & \multirow{2}{*}{$\begin{array}{l}\mathrm{Q}, \\
1 / \mathrm{s}\end{array}$} & \multirow{2}{*}{$\begin{array}{l}\mathrm{P}_{\mathrm{G}}, \\
\mathrm{mPa}\end{array}$} & \multirow{2}{*}{$\begin{array}{c}\mathrm{p} \\
\mathrm{kg} / \mathrm{m}^{3}\end{array}$} & \multirow{2}{*}{$\begin{array}{l}\mathrm{T}, \\
\mathrm{s}\end{array}$} & \multicolumn{2}{|c|}{ FANN35 } & \multicolumn{2}{|c|}{ ETTA1 } \\
\hline & & & & & & & $\begin{array}{c}\eta . \\
\mathrm{Pa}^{*} \mathrm{~s}\end{array}$ & $\begin{array}{c}\tau, \\
\mathrm{Pa}\end{array}$ & $\begin{array}{c}\eta \\
\text { Pa*s }\end{array}$ & $\begin{array}{c}\tau, \\
\mathrm{Pa}\end{array}$ \\
\hline 1525 & 1075 & 8.3 & 32 & 12.8 & 1330 & 26.32 & 0.014 & 3.84 & 0.0097 & 13.08 \\
\hline
\end{tabular}

Table 6. Estimated pressure losses

\begin{tabular}{|l|l|l|l|l|l|l|l|l|l|l|l|}
\hline Method & $\begin{array}{l}\mathrm{P}_{\mathrm{P}}, \\
\mathrm{mPa}\end{array}$ & $\begin{array}{l}\mathrm{P}_{\mathrm{J}}, \\
\mathrm{mPa}\end{array}$ & $\begin{array}{l}\mathrm{P}_{\mathrm{PW}}, \\
\mathrm{mPa}\end{array}$ & $\begin{array}{l}\mathrm{P}_{\mathrm{PC}}, \\
\mathrm{mPa}\end{array}$ & $\begin{array}{l}\mathrm{P}_{\mathrm{C}}, \\
\mathrm{mPa}\end{array}$ & $\begin{array}{l}\mathrm{P}_{\mathrm{CW}}, \\
\mathrm{mPa}\end{array}$ & $\begin{array}{l}\mathrm{P}_{\mathrm{B}}, \\
\mathrm{mPa}\end{array}$ & $\mathrm{P}_{\mathrm{S}}, \mathrm{mPa}$ & $\begin{array}{l}\mathrm{P}, \mathrm{mPa} \\
\%\end{array}$ & $\begin{array}{l}\mathrm{P}-\mathrm{PM} \\
\mathrm{mPa}\end{array}$ & -1.22 \\
\hline FANN35 & 7.22 & 1.63 & 0.24 & 0.10 & 1.56 & 0.13 & 0.64 & 0.05 & 11.58 & -8.1 \\
\hline ETTA1 & 7.38 & 1.63 & 0.35 & 0.15 & 1.56 & 0.14 & 0.64 & 0.05 & 11.91 & -0.89 & -6.9 \\
\hline
\end{tabular}

Note: $\mathrm{P}_{\mathrm{P}}$ is the pressure loss inside the drill pipes; $\mathrm{P}_{\mathrm{J}}$ is the pressure loss in their joints; $\mathrm{P}_{\mathrm{PW}}$ is the pressure loss between the drill pipe and the well; $\mathrm{P}_{\mathrm{PC}}$ is the pressure loss between the conductor and the well; $\mathrm{P}_{\mathrm{C}}$ is the pressure loss inside the drill collar; $\mathrm{P}_{\mathrm{CW}}$ is the pressure loss between the drill collar and the well; $\mathrm{P}_{\mathrm{B}}$ is the pressure loss on the drilling bit nozzle; $\mathrm{P}_{\mathrm{S}}$ is the pressure loss of removing sludge particles.

Therefore, for four of the eight sections of the circulation system indicated in the graphs, the pressure losses obtained by the developed method are higher than those based on the FANN35 device readings; for the rest of them they are the same. The total losses are $2.8 \%$ higher. At the same time, the total pressure losses calculated by FANN35 deviate from the gauge readings on the drilling pump by $8.1 \%$, while those calculated by ETTA1 deviate by only $6.9 \%$, i.e., in this case, as shown by the production tests, the accuracy of the proposed method is no worse than that of Fann35.

\section{CONCLUSIONS}

Based on the results of the comparative studies, it can be concluded that a very simple and low cost method has been created for measuring the plastic viscosity and yield point of the drilling fluid. The proposed method does not require special equipment, while being based on the use of simple and widely used tools for measuring density and relative viscosity. It does not need special measuring procedures, allowing using the results of routine density and relative viscosity measurements. The method does not impose special, sharply increased requirements for the accuracy of measuring the time of fluid outflow from the funnel. It also does not require any additional funnel measurements of the flow time and gauging volumes.
With the known geometrical parameters of the funnel, the true viscosity parameters are calculated using simple formulas. For example, for the VBR-2 funnel, they are as follows:

$$
\eta=12.73 * 10^{-8 *}\left(2.84-456.4 / \mathrm{T}^{2}\right) * \mathrm{~T}^{*} \rho
$$

$$
\tau=35420 * \eta / T
$$

The experimental studies comparing the viscosity parameters using the proposed express method with the FANN35 rheometer readings confirm that there is a strong convergence between the final results of plastic viscosity and yield point measurements.

The production tests comparing the actual pressure losses in the circulation system of a drilled well using a pump pressure gauge with the calculations of the sum of the pressure losses along the fluid circulation path using the considered method show in general a satisfactory convergence of the results.

\section{REFERENCES}

[1] Schoesser B, Thewes M. Marsh Funnel testing for rheology analysis of bentonite slurries for Slurry Shields. "SEE Tunnel: Promoting Tunneling in SEE Region" ITA WTC 2015 Congress and 41st General Assembly May 22-28, 2015. Lacroma Valamar Congress Center, Dubrovnik, Croatia. 
International Journal of Engineering Research and Technology. ISSN 0974-3154, Volume 13, Number 1 (2020), pp. 58-65

(C) International Research Publication House. http://www.irphouse.com

[2] Pitt MJ. The Marsh Funnel and drilling fluid viscosity: a new equation for field field use. Soc. of Pet. Eng., Drill. Complet. 2000; 15: 3-6.

[3] Ochoa MV. Analysis of drilling fluid rheology and tool joint effect to reduce errors in hydraulics calculations. $\mathrm{PhD}$ dissertation. Texas A\&M University, 2016.

[4] Rogov YeI, Kussainov AA, Gumenyuk VV. Physical models of solid mass and related processes in interaction with foundations. Journal of Mechanical Engineering Research and Developments. 2018; 41(2): 65-74.

[5] Balhoff MT, Lake LW, Bommer PM, Lewis RE, Weber MJ, Calderin JM. Rheological and yield stress measurements of non-Newtonian fluids using a Marsh Funnel. J. Pet. Sci. Eng. 2011; 77: 393-402.

[6] Makovey N. Drilling hydraulics. Moscow, Nedra, 1986.

[7] Ziyadin S, Shash N, Levchenko T., Khudaibergenova S., Yessenova G. Modeling of resultant effects in assessment of innovative activity of the hotel organization. Entrepreneurship and Sustainability Issues. 2019; 6(4): 2180-2193.

[8] Guria C, Kumar R, Mishra P. Rheological analysis of drilling fluids using Marsh funnel. Journal of Petroleum Science and Engineering. 2013; 105: 62-69.

[9] Mishchevich VI, Sidorov NA. Handbook of a drilling engineer. Vol. I. Moscow, Nedra, 1973.

[10]Biletskiy MT, Ratov BT, Syzdykov AK., Delikesheva DN. Express Method for measuring the drilling muds rheological parameters. 19th International multidisciplinary scientific geoconference (Science and Technologies in Geology, Exploration and Mining. 2019; 19 (1.2): 861-868

[11] Marsh H. Properties and Treatment of Rotary Mud. Petroleum Development and Technology, Transactions of the AIME. 1931: 234-251.

[12] Roussel N, Roy BL. The Marsh cone: a test or a rheological apparatus? Cem. Concr. Res. 2005; 35: 823830.

[13] Mitelman BI. Handbook of hydraulic calculations in drilling. Moscow, Gostoptekhizdat, 1963.

[14] Agzamov FA, Kabdushev A, Komleva SF, Bayutenov A. Polyelectrolytes Efficiency in Grout Property Regulation. Key Engineering Materials. 2018; 771, 9-23. 